\title{
Diagnostic Yield of Computed Tomography-Guided Transthoracic Lung Biopsy in Diffuse Lung Diseases
}

\author{
Eva Padrão ${ }^{a}$ Márcio Rodrigues ${ }^{b}$ Susana Guimarães ${ }^{c}$ Patrícia Caetano Mota ${ }^{a} d$ \\ Natália Melo ${ }^{a}$ Conceição Souto Mourac, d António Morais ${ }^{\mathrm{a}}{ }^{\mathrm{d}}$ \\ José Miguel Pereirab, $d$ \\ ${ }^{a}$ Department of Pulmonology, Centro Hospitalar de São João, Porto, Portugal; ${ }^{b}$ Department of Radiology, Centro \\ Hospitalar de São João, Porto, Portugal; ' Department of Pathology, Centro Hospitalar de São João, Porto, Portugal; \\ dFaculty of Medicine, University of Porto, Porto, Portugal
}

\section{Keywords}

Computed tomography-guided transthoracic lung biopsy · Complications - Diagnostic yield · Diffuse lung diseases . Organizing pneumonia $\cdot$ Surgical lung biopsy

\begin{abstract}
Background: Accurate diagnosis is essential for successful management of diffuse lung disease (DLD). Histopathology may sometimes be necessary. Surgical lung biopsy, the gold standard, carries a risk of morbidity and mortality. Computed tomography (CT) guided transthoracic lung biopsy (CT-TLB) is a minimally invasive method for obtaining lung tissue. However, its diagnostic yield is unknown in DLD. Objective: To assess the diagnostic yield of CT-TLB in DLD according to the predominant high-resolution CT (HRCT) patterns. Methods: Between January 2009 and December 2016, we enrolled all consecutive adult patients with suspicion of DLD who underwent $\mathrm{CT}$-guided transthoracic lung biopsy during the diagnostic work-up. All biopsies were performed by a senior interventional radiologist using CT fluoroscopy. $\boldsymbol{R e}$ sults: The study included 169 patients (50.3\% men) with a mean $( \pm S D)$ age of $58.3 \pm 14$ years. Consolidation was the
\end{abstract}

\section{KARGER}

(c) 2018 S. Karger AG, Basel

E-Mail karger@karger.com

www.karger.com/res predominant HRCT pattern. A definitive or probable diagnosis was made in $66.3 \%$. The most frequent diagnosis was organizing pneumonia (36.2\%). Diagnostic yield was higher when the predominant HRCT pattern was consolidation or nodular. The most common complication was pneumothorax (17.8\%); other complications included mild hemoptysis (7.7\%), hemothorax (1.2\%), and death (0.59\%). No acute exacerbation of the underlying condition was observed. Conclusions: CT-TLB proved to be accurate and safe for the diagnosis of DLD. The overall diagnostic yield of the procedure was $66.3 \%$. Given its low complication rates, CT-TLB can be an option in patients whose respiratory function is seriously impaired and in those with substantial comorbidities, where more invasive procedures cannot be performed for reasons of safety.

(c) 2018 S. Karger AG, Basel

\section{Introduction}

Diffuse lung disease (DLD) comprises a large and heterogeneous group of acute and chronic diseases that predominantly affect the pulmonary interstitium [1-3]. 
Establishing an accurate and confident diagnosis, while frequently challenging, is essential for the successful management of patients with DLD [1-3]. Therefore, a multidisciplinary approach should be taken and based on clinical data, laboratory tests, and functional, imaging, and histopathological findings [4-6]. While the diagnosis can be established on the basis of compatible clinical and radiologic findings combined with specific bronchoalveolar lavage (BAL) findings, it may be necessary to use histopathology, which is more invasive $[1,4,5]$. Transbronchial lung biopsy can be an appropriate initial procedure, although its diagnostic accuracy is highly variable and depends on a range of factors, such as disease distribution, crush artifacts, and sample size, which might not be representative of the predominant process; therefore, it is not considered useful in a significant number of DLDs $[4,5,7$, 8]. Several recent publications have reported on the high diagnostic accuracy of transbronchial lung cryobiopsy (TBLC), a bronchoscopic procedure that yields sufficiently large and high-quality lung samples [9-12]. Most recommendations and published data refer to surgical lung biopsy (SLB) and its diagnostic yield in DLD $[4,5,7]$. However, this approach may increase morbidity and mortality and requires appropriate patient selection, taking into account age, comorbidities, functional status, and disease severity; consequently, in many cases it is unlikely to be performed [13-16]. Computed tomography (CT)-guided transthoracic lung biopsy, a minimally invasive method, is an option for obtaining lung tissue that significantly reduces the morbidity of more invasive approaches such as SLB. Few data have been reported on the value of CT-guided transthoracic lung biopsy in the diagnosis of DLD, and its actual diagnostic yield in this context is unknown.

\section{Aims}

The aim of this study was to evaluate the diagnostic yield of CT-guided transthoracic lung biopsy in patients with DLD based on the predominant patterns in high-resolution CT (HRCT). We also analyzed its role in the multidisciplinary approach of this group of diseases and associated complications.

\section{Materials and Methods}

\section{Subjects and Diagnostic Procedures}

We included all consecutive adult patients ( $\geq 18$ years) whose HRCT scan showed features of diffuse lung involvement and who underwent a CT-guided transthoracic lung biopsy during their diagnostic work-up at a tertiary referral center, Centro Hospitalar de São João, from January 2009 through December 2016. Before pro- posing the procedure, each case was discussed at a multidisciplinary meeting. All participants provided their written informed consent after an explanation of the purpose and methodology of the biopsy procedure, its associated risks, and possible adverse outcomes. The study was approved by the Institutional Review Board of Centro Hospitalar de São João.

Patients underwent a complete blood count, with platelet count, basic blood biochemistry, and a coagulation study. Anticoagulant and antiplatelet therapy had been discontinued.

All lung biopsies were performed by a senior interventional radiologist using CT fluoroscopy. The biopsies were taken with an 18-gauge automated cutting needle after administration of local anesthesia with a subcutaneous injection of $5 \mathrm{~mL}$ of $2 \%$ lidocaine. In most of the biopsies, only one specimen was obtained, with a maximum of 2 specimens per procedure.

After the procedure, each patient was transferred to the ward and positioned in such a way that the biopsy puncture site was in the dependent position. A chest radiograph was performed within $2 \mathrm{~h}$ to identify possible complications. If there was no evidence of complication (pneumothorax, hemoptysis, hemorrhage) the patient was discharged on the day of the procedure. Asymptomatic patients with mild pneumothorax were followed with no intervention. A chest tube was inserted in symptomatic patients and in those with evidence of large or increasing pneumothorax.

Clinical, Radiological, and Functional Assessment, BAL, and Histopathology

Clinical data and demographic information were obtained from electronic medical records. A retrospective analysis of the information recorded was performed, taking into account clinical data, smoking habits, predominant HRCT pattern, respiratory function tests, BAL features, histopathology findings, procedure complications, and need for further study, namely, SLB.

The HRCT pattern was classified as micronodular, nodular, ground-glass opacity, reticulation, consolidation, mass, cystic, and mosaic according to the glossary of the Fleischner Society [17]. Patterns were also classified as combined if equally dominant.

Pulmonary function tests were performed in accordance with the standard recommendations of the American Thoracic Society (ATS) and European Respiratory Society (ERS) and findings categorized as normal, obstructive, restrictive, or mixed abnormalities [18].

BAL was performed following the recommendations of the ERS [19]. BAL cellular patterns were classified as lymphocytic $(>15 \%)$, neutrophilic $(>3 \%)$, and eosinophilic $(>1 \%)$.

Biopsy specimens were processed and stained for histopathology. Samples were considered nonrepresentative if there was inadequate or insufficient tissue. A histopathological analysis was performed only in biopsy specimens that met the minimal criteria of acceptability (at least $10-20 \mathrm{~mm}$ in length and at least $1 \mathrm{~mm}$ in width). If the biopsy specimens met sufficient histopathologic criteria to define a specific DLD pattern, a histologic diagnosis was established. When only some specific pathologic features of a specific DLD were present but criteria were incomplete, the diagnosis was classed as probable. Samples that lacked major histopathologic criteria for establishing a pattern of DLD were considered nonspecific/nondiagnostic.

DLDs were classified case by case after discussion at a multidisciplinary meeting, taking into account the current international consensus criteria of the ATS and the ERS $[4,5]$. 
Statistical Analysis

All data analyses were performed using SPSS version 21.0 (IBM SPSS Statistics for Windows, version 21.0, IBM Corp., Armonk, NY, USA). Exploratory and descriptive analyses were applied to the variables. For each comparison, $p$ values were calculated and considered statistically significant if less than 0.05 .

\section{Results}

The study population included 169 patients with a mean $( \pm \mathrm{SD})$ age of $58.3 \pm 14$ years (range $18-85$ years). Of these, 85 (50.3\%) were men and 91 (53.9\%) had a history of smoking. Pulmonary function testing revealed ventilatory abnormalities in $51.7 \%$ of subjects. Diffuse lung capacity for carbon monoxide $\left(\mathrm{D}_{\mathrm{L}} \mathrm{CO}\right)$ was impaired in $67.2 \%$, in whom the mean $( \pm S D)$ percentage of predicted $\mathrm{D}_{\mathrm{L}} \mathrm{CO}$ was $53.1 \pm 14.8 \%$ (Table 1 ). A differential cell count was performed in BAL in 115 patients $(68 \%)$ and revealed lymphocytosis to be the most frequent feature. General demographic information and clinical characteristics are summarized in Table 1.

The most frequent predominant HRCT pattern was consolidation, which was seen in $29 \%$ of patients. The other notable CT patterns included nodular (13\%), micronodular (10\%), ground-glass opacity $(7.7 \%)$, cystic $(6.5 \%)$, reticulation $(6.5 \%)$, and combination of patterns (24.9\%). The main CT features are shown in Table 2.

The diagnostic accuracy of CT-guided transthoracic lung biopsy is shown in Table 3. Sufficient histopathologic tissue was obtained in $92.9 \%$ of patients. A definitive or probable diagnosis was confirmed in $66.3 \%$ of patients.

In the case of patients with a histopathology-based definitive/probable diagnosis $(n=112)$, the most frequent diagnosis was organizing pneumonia $(\mathrm{OP})$, which was detected in $36.2 \%$, followed by sarcoidosis, silicosis, acute fibrinous and OP, eosinophilic pneumonia, hypersensitivity pneumonitis (HP), pleuroparenchymal fibroelastosis (PPFE), and usual interstitial pneumonia (UIP). The remaining detailed information on the histopathologic diagnosis is listed in Table 4. Figures 1-3 illustrate 3 cases in which the diagnosis was based on a CT-guided transthoracic lung biopsy.

CT-guided transthoracic lung biopsy had a significantly higher diagnostic yield when the predominant HRCT pattern was consolidation $(p<0.01)$. In these cases, the yield was $87.7 \%$. A nodular pattern also indicated a high diagnostic yield (77.3\%). A ground-glass opacity or cystic pattern was significantly associated with a nondiagnostic CT-guided transthoracic lung biopsy $(p=0.018$
Table 1. Demographic and clinical characteristics

\begin{tabular}{|c|c|}
\hline Variable & Total \\
\hline Age, years, mean $\pm S D$ & $58.3 \pm 14$ \\
\hline \multicolumn{2}{|l|}{ Gender, $n(\%)$} \\
\hline Male & $85(50.3)$ \\
\hline Female & $84(49.7)$ \\
\hline \multicolumn{2}{|l|}{ Smoking habits, $\%$} \\
\hline Nonsmoker & 46 \\
\hline Ex-smoker & 30.2 \\
\hline Smoker & 23.7 \\
\hline Pack-years, mean \pm SD & $36.6 \pm 30.5$ \\
\hline \multicolumn{2}{|l|}{ Pulmonary function pattern, $\%$} \\
\hline Normal & 48.3 \\
\hline Obstructive & 25.9 \\
\hline Restrictive & 22.4 \\
\hline Mixed & 3.4 \\
\hline \multicolumn{2}{|l|}{ Diffuse lung capacity for carbon monoxide } \\
\hline Decreased, $\%$ & 67.2 \\
\hline Percentage of predicted, mean \pm SD & $53.1 \pm 14.8$ \\
\hline Normal & 32.8 \\
\hline Percentage of predicted, mean \pm SD & $87 \pm 10.8$ \\
\hline \multicolumn{2}{|l|}{ Bronchoalveolar lavage cellular pattern, \% } \\
\hline Normal & 21.9 \\
\hline Lymphocytic & 27.6 \\
\hline Eosinophilic & 13.3 \\
\hline Neutrophilic & 12.4 \\
\hline Lymphocytic and neutrophilic & 9.5 \\
\hline Neutrophilic and eosinophilic & 8.6 \\
\hline Lymphocytic and eosinophilic & 6.7 \\
\hline
\end{tabular}

Table 2. Radiologic evaluation

\begin{tabular}{lc}
\hline Predominant high-resolution CT pattern & Total, $n(\%)$ \\
\hline Consolidation & $49(28.99)$ \\
Nodular & $22(13.02)$ \\
Micronodular & $17(10.06)$ \\
Ground-glass + consolidation & $16(9.47)$ \\
Ground-glass + reticulation & $16(9.47)$ \\
Ground-glass & $13(7.69)$ \\
Cystic & $11(6.51)$ \\
Reticulation & $11(6.51)$ \\
Reticulation + honeycombing & $5(2.96)$ \\
Reticulation + honeycombing + ground-glass & $5(2.96)$ \\
Mass & $2(1.18)$ \\
Mosaic & $2(1.18)$ \\
\hline
\end{tabular}

and $p=0.009$, respectively). The overall diagnostic yield of the technique according to the predominant HRCT pattern is shown in Table 5.

Among subjects with nondiagnostic biopsies $(n=45)$, 11 subsequently underwent a second CT-guided transthoracic lung biopsy, 7 (58.4\%) of which confirmed the 
Table 3. Diagnostic accuracy of CT-guided transthoracic lung biopsy

\begin{tabular}{lc}
\hline Variable & Total, $n(\%)$ \\
\hline Definite diagnosis & $102(60.4)$ \\
Probable diagnosis & $10(5.9)$ \\
Nondiagnostic & $45(26.6)$ \\
Nonrepresentative & $12(7.1)$ \\
\hline
\end{tabular}

Table 4. Histopathologic diagnosis obtained $(n=112)$

\begin{tabular}{lr}
\hline Variable & Total, $n(\%)$ \\
\hline OP & $42(37.5)$ \\
Sarcoidosis & $11(9.82)$ \\
Silicosis/silicoanthracosis & $11(9.82)$ \\
AFOP & $10(8.93)$ \\
Eosinophilic pneumonia & $6(5.36)$ \\
HP & $6(5.36)$ \\
PPFE & $6(5.36)$ \\
UIP & $6(5.36)$ \\
Vasculitis & $4(3.57)$ \\
Langerhans cell histiocytosis & $2(1.79)$ \\
Rheumatoid nodule & $2(1.79)$ \\
NSIP & $1(0.89)$ \\
RB-ILD & $1(0.89)$ \\
Other & \\
$\quad$ Amyloid tumor & $1(0.89)$ \\
$\quad$ Emphysema & $1(0.89)$ \\
$\quad$ GMV infection & $1(0.89)$ \\
$\quad \quad$ of MAC infection & $1(0.89)$ \\
\hline
\end{tabular}

a Two cases were positive for antineutrophil cytoplasmic antibody (ANCA) to myeloperoxidase (MPO), one was positive for ANCA proteinase 3 (PR3) and one was negative for ANCA.

AFOP, acute fibrinous and organizing pneumonia; CMV, cytomegalovirus; HP, hypersensitivity pneumonitis; MAC, Mycobacterium avium complex; NSIP, nonspecific interstitial pneumonia; OP, organizing pneumonia; PPFE, pleuroparenchymal fibroelastosis; RB-ILD, respiratory bronchiolitis interstitial lung disease; UIP, usual interstitial pneumonia.

following diagnoses: antineutrophil cytoplasmic antibody (ANCA) to myeloperoxidase (MPO) vasculitis $(n=$ 2), OP, eosinophilic pneumonia, lipoid pneumonia, hyalinizing granuloma, and connective tissue disease-related interstitial lung disease (rheumatoid arthritis). Another 13 patients were referred for SLB, which confirmed the diagnosis in 11 cases (84.6\%), as follows: HP $(n=5)$, OP $(n=2)$, respiratory bronchiolitis interstitial lung disease $(n=2)$, pulmonary hemosiderosis $(\mathrm{n}=1)$, and epithelioid hemangioendothelioma $(n=1)$. Of note, in the last 2 cas- es, the diagnosis had already been suggested by the CTguided transthoracic lung biopsy, although SLB was performed to confirm the diagnosis.

Most of CT-guided transthoracic lung biopsy procedures $(72.8 \%, n=123)$ were performed without complications. The most common complication was pneumothorax, which developed in 30 biopsy procedures (17.8\%). In 9 cases (30\%) it was necessary to insert a chest drain; the remaining cases improved spontaneously, without intervention. Mean prolonged hospital stay due to this complication was about $4 \pm 3$ days. Mild hemoptysis occurred in $7.7 \%$ of patients and hemothorax in $1.2 \%$. None of the events reported was life-threatening. No acute exacerbation of the underlying condition was observed. Only one procedure-related death (gas embolism) was reported. Significantly more complications were observed in patients with decreased $\mathrm{D}_{\mathrm{L}} \mathrm{CO}(p=0.031)$, although no differences in the HRCT pattern were observed $(p>0.05)$.

\section{Discussion}

We found that CT-guided transthoracic lung biopsy proved to be an accurate and safe procedure for the diagnosis of DLD. The overall diagnostic yield of CT-guided transthoracic lung biopsy in this cohort of patients with suspected DLD was $66.3 \%$; the procedure proved more sensitive when the radiologic pattern was consolidation or nodular.

Most published data on CT-guided transthoracic lung biopsy to date are on lung nodules or masses, which are mainly assessed to determine whether they are benign or malignant. In this context, this technique has widespread acceptance as a preferred method of diagnosis, since it has already been demonstrated to be significantly accurate and safe [20-24]. The diagnostic yield of CT-guided transthoracic lung biopsy in nodules or masses has been reported to be as high as 95\% [23-26].

The multidisciplinary meeting is currently the gold standard when establishing a diagnosis of DLD [4-7,27]. This approach has significantly improved diagnostic accuracy, overall agreement, and diagnostic confidence $[6$, 28]. When DLD is suspected, the information recorded (history, physical examination, thoracic imaging, lung function, and other tests [e.g., BAL data]) must be thoughtfully reviewed and analyzed. When these investigations are considered to be insufficient to provide a confident diagnosis, additional and more invasive procedures, such as lung biopsy, are useful $[4,5,7]$. Until recently, SLB was considered the recommended diagnostic procedure in 

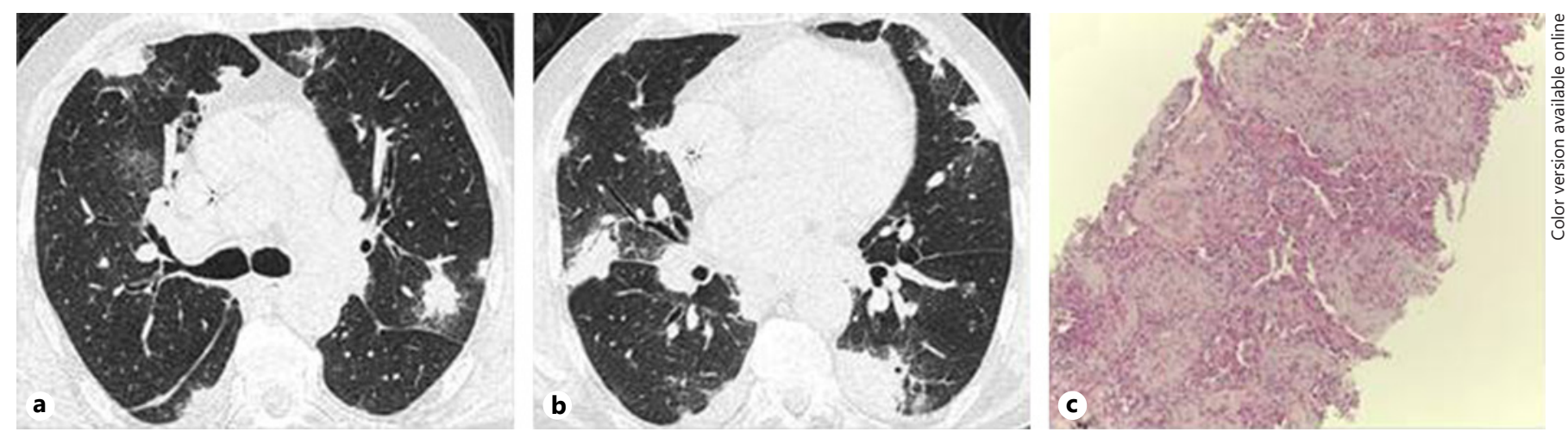

Fig. 1. Organizing pneumonia secondary to amiodarone-induced toxicity in a 75-year-old man. a, b Axial HRCT images demonstrate the presence of bilateral multifocal consolidations, with a predominant peripheral and peribronchial distribution; some of the consolidation foci present a surrounding ground-glass halo. c Transthoracic lung biopsy sample showing airspaces filled with plugs of loose fibroblasts, inflammatory cells, and myxoid stroma $(\mathrm{H} \& \mathrm{E}, \times 100)$.
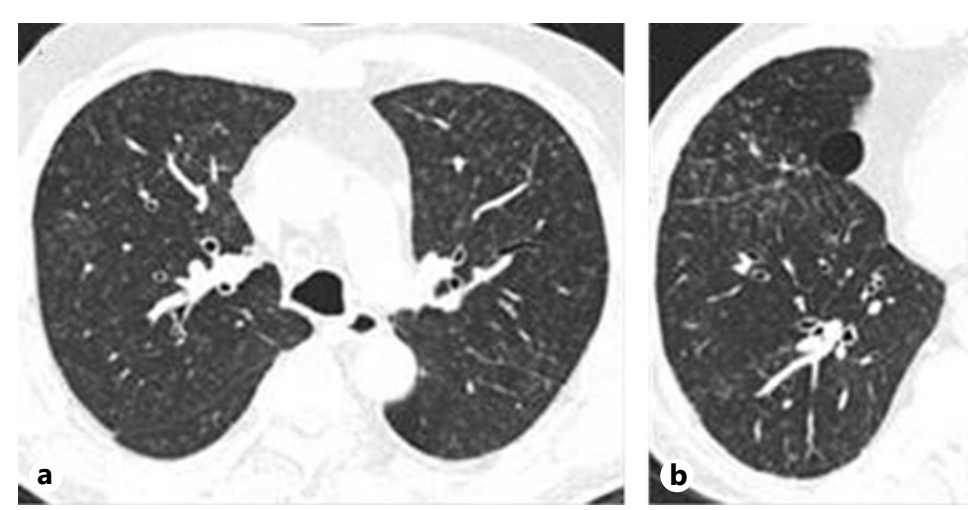
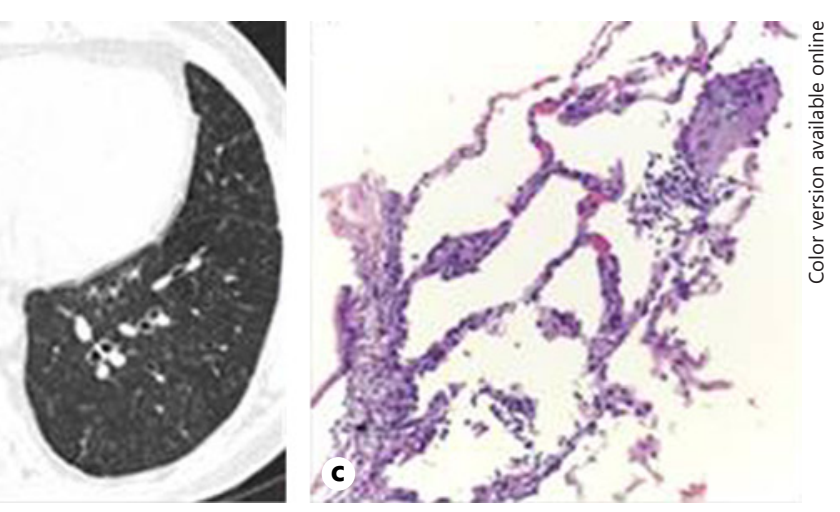

Fig. 2. Hypersensitivity pneumonitis (HP) in a 61-year-old man who had been exposed to pigeons and had a previous medical history of non-Hodgkin lymphoma treated with chemotherapy. a, b Multiple centrilobular nodules with ground glass attenuation scat- tered throughout the lungs. A small cyst is noted in the right middle lobe. c Transthoracic lung biopsy sample showing lymphocytic infiltrate in the alveolar walls, a small poorly formed granuloma and organizing pneumonia $(\mathrm{H} \& \mathrm{E}, \times 200)$.
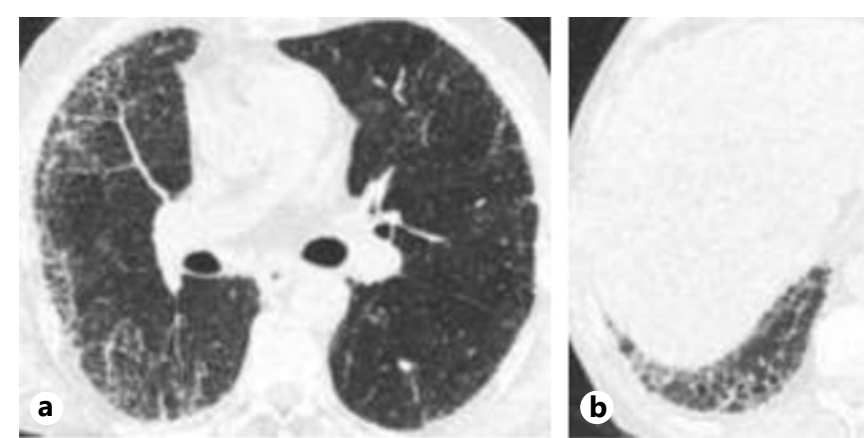

Fig. 3. Idiopathic pulmonary fibrosis in a 73-year-old man. a, b Axial HRCT images show extensive reticulation and multilayered subpleural honeycombing with traction bronchiectasis. Asymmetry is noted, with more pronounced findings in the right lung. No
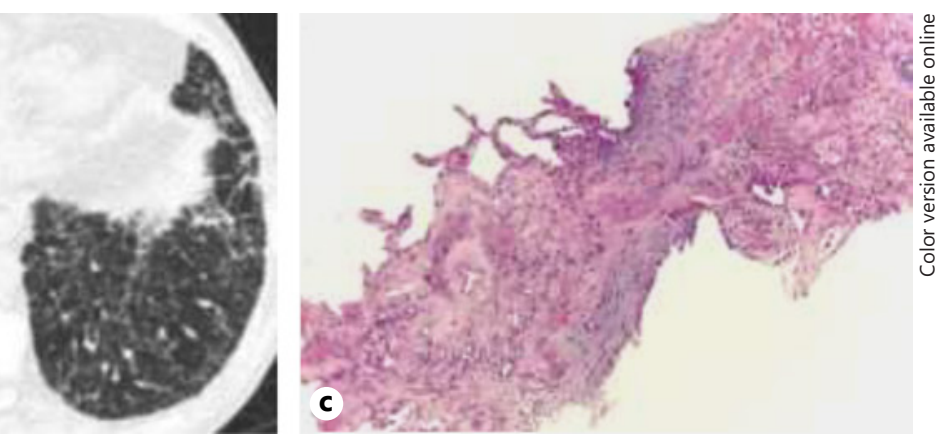

inconsistent features are seen. c Transthoracic lung biopsy sample showing collagenous fibrosis with transition to preserved parenchyma (not shown), fibroblastic foci, and mild chronic interstitial inflammation; no honeycombing $(\mathrm{H} \& \mathrm{E}, \times 200)$. 
Table 5. Diagnostic yield of CT-guided transthoracic lung biopsy according to the predominant HRCT pattern

\begin{tabular}{ll}
\hline HRCT pattern & Diagnostic yield, \%* \\
\hline Consolidation & 87.7 \\
Nodular & 77.3 \\
Ground-glass + consolidation & 75 \\
Micronodular & 64.7 \\
Reticulation & 54.6 \\
Ground-glass & 38.5 \\
Ground-glass + reticulation & 31.2 \\
Cystic & 27.3 \\
\hline
\end{tabular}

* Definite and probable diagnosis.

DLD. In fact, the role of SLB is well established in DLD [13]. Published data show that, in most cases, a confident diagnosis was reached in more than $90 \%$ of patients who underwent SLB [13, 29-31]. However, despite the high diagnostic yield of this procedure, associated morbidity and mortality are high, mainly because of acute exacerbation of the underlying disease $[13,14,31-36]$. Therefore, the procedure may not be feasible in patients with serious comorbidities or severe disease. Moreover, TBLC is increasingly used in the diagnosis of DLD and has a diagnostic yield of between 75 and $85 \%$, or even higher in some series [11, 12,37-39]. Even in cases of fibrosing DLD, with a UIP or UIP-like HRCT pattern, in which the differential diagnosis is more problematic, TBLC has also provided a good diagnostic yield [12].

Few data are available on the role of CT-guided transthoracic lung biopsy for the diagnosis of DLD, and reports almost only refer to its role in OP, in which the technique has been used for diagnosis in isolated cases [4042]. The procedure was also reported in a small cohort of patients for the diagnosis of PPFE and was considered a valuable tool in this context [43]. Our literature search revealed only 2 small series on CT-guided transthoracic lung biopsy for diagnosing DLD, in which the authors made an etiological diagnosis in about $80 \%$ and $73 \%$ of cases $[44,45]$. However, their relatively small sample sizes ( $n=15$ and $n=22$, respectively) inevitably limit the interpretation of these results owing to potential sampling biases. Although the overall diagnostic yield of our study is slightly lower than those cited, we emphasize that, to the best of our knowledge, ours is the largest cohort in which the role of CT-guided transthoracic lung biopsy has been established in patients with suspected DLD and the only one to show a clear correlation between HRCT pattern and diagnostic yield.
The diagnosis of patients who underwent CT-guided transthoracic lung biopsy was established after evaluation at the multidisciplinary meeting, where the histological pattern was contextualized with both clinical and radiological features. Diagnosis based on histopathology (Table 4) was reliable in some cases, such as OP, sarcoidosis, and acute fibrinous and OP, whereas other cases (e.g., UIP or nonspecific interstitial pneumonia pattern [NSIP]) were more complex, usually required larger samples, and could not be diagnosed with a high degree of confidence. The initial diagnosis was HP in 6 patients, although in 3, histology findings were considered low-confidence, and the final diagnosis was only established at the multidisciplinary meeting. The other 3 were considered high confidence, since an interstitial infiltrate was present in all 3 (associated with granulomas in 2 and with OP in 2). As for the UIP pattern, it is noteworthy that none of these patients could undergo SLB because of their comorbidities. Six patients were considered to have a UIP pattern; of these, 2 had patchy fibrosis associated with fibroblastic foci and honeycombing, 2 had patchy fibrosis with fibroblastic foci, and one patchy fibrosis with honeycombing, which can be considered a high-confidence diagnosis. One of the patients, however, had patchy fibrosis, which enables a low-confidence diagnosis, and a definitive diagnosis was obtained only after the multidisciplinary evaluation. After the multidisciplinary meeting, 2 of these cases of UIP were assumed to be in the context of HP, whereas the remaining in the context of idiopathic pulmonary fibrosis. In the only patient diagnosed with NSIP, the histology sample revealed diffuse interstitial fibrosis with a significant inflammatory infiltrate and aggregates of lymphocytes and plasmocytes that were consistent with his rheumatoid arthritis. In this case, transthoracic lung biopsy had been performed as part of a differential diagnosis with imaging features analyzed previously in the multidisciplinary meeting. Of the 4 cases with vasculitis, 2 proved to be ANCA MPO+ and one ANCA PR3+. All 3 underwent transthoracic lung biopsy, which revealed granulomatous vasculitis and capillaritis with hemosiderosis in the first 2. In the ANCA PR3+ case, the biopsy showed hemosiderosis and capillaritis. Two of these cases corresponded to patients who initially (at onset of disease) were ANCA- negative; ANCA titers were shown to be positive during the course of the disease and after the CT-guided transthoracic lung biopsy. In both cases, ANCA values remained only feebly positive. The other patient was admitted to hospital with persistent fever of unknown origin. In addition to the identification of ANCA positivity, a superinfection gave cause for concern 
and led to the CT-guided transthoracic lung biopsy. One patient with a final diagnosis of granulomatosis with polyangiitis was ANCA-negative, and the diagnosis was based on pulmonary hemorrhage in the biopsy and extrapulmonary features compatible with vasculitis.

One could question whether the result of this study would have been more robust if subsequent surgical biopsy specimens had been used to validate the diagnostic accuracy of CT-guided biopsy. However, as previously mentioned, given the high degree of confidence when establishing the diagnosis in the cases presented in this series, it would not be ethical to pursue to SLB merely to validate the diagnosis, since it would eventually (and needlessly) contribute to an increased risk of complications. Moreover, it should be noted that cases in which it was not possible to establish a diagnosis with a high degree of confidence after CT-guided transthoracic lung biopsy were subsequently referred for SLB, unless this was not feasible owing to safety concerns.

Complications of CT-guided transthoracic lung biopsy were detected in $27.2 \%$ of cases, which is consistent with the literature. The most common complication was pneumothorax (17.8\%), followed by mild hemoptysis (7.7\%) and hemothorax (1.2\%); these data are in line with other reports on this technique, even though reported complication rates are highly variable $[21,25,26,46]$. Apart from the patient who died from procedure-related complication, none of the other events that occurred in our study were considered life-threatening for patients undergoing CT-guided transthoracic lung biopsy. Conversely, SLB, a widely accepted and costly procedure, may unnecessarily increase the risk of serious complications in some cases. In fact, it carries considerable risks, namely, an overall mortality of $2-6 \%$ and an associated morbidity of approximately $10-20 \%$, both of which are largely associated with the occurrence of acute exacerbation $[13,14,31,32,34,35,47,48]$. In the present cohort, it should be noted that there were no exacerbations after CT-guided transthoracic lung biopsy. In fact, concerns about morbidity and mortality and risk of exacerbation are a major constraint when selecting patients for histological assessment to resolve an inconclusive diagnosis. The decision to perform a lung biopsy should always be taken on an individual basis, weighing the potential risks inherent to the procedure against the benefit of establishing a confident diagnosis. In fact, it is not uncommon for patients with suspected DLD in whom SLB is deemed necessary to be excluded from this procedure owing to serious comorbidities or severe lung disease, since the risk of complications may outweigh the potential benefits of

Diagnostic Yield of CT-Guided

Transthoracic Lung Biopsy in DLD biopsy. Additionally, as SLB is invasive and is associated with significant morbidity and mortality, many patients frequently do not consent to undergo the procedure. In this context, CT-guided transthoracic lung biopsy might be considered an appropriate method for histological assessment. One of the main advantages of the procedure is that it can be performed under local anesthesia, without the need for deep sedation or intubation. Thus, CT-guided transthoracic lung biopsy can be envisaged for patients with severely impaired respiratory function and substantial comorbidities. As the technique is minimally invasive, it reduces the risk of complications and life-threatening events.

Our study is limited by its retrospective design. It is also subject to a certain degree of selection bias, because of the intrinsic notion that CT-guided transthoracic lung biopsy could be particularly sensitive for the diagnosis of patients whose HRCT patterns are characterized by consolidations and nodules, which are the main radiologic findings registered in this cohort. This selection bias became even more evident after the introduction of TBLC in our center. In addition, OP was the most frequent diagnosis in the cohort, although this does not fully represent the patients followed at our DLD outpatient clinic. Furthermore, and while inherent to the technique, the dimensions of the lung tissue samples obtained through CT-guided transthoracic lung biopsy tend to be significantly smaller than those sampled through SLB, thus affecting the diagnostic accuracy of the former. In fact, in the present study, CT-guided transthoracic lung biopsy did not provide an accurate diagnosis in $26.6 \%$ of patients. However, it must be noted that when a patient undergoes CT-guided transthoracic lung biopsy, tissue sampling is guided directly onsite. With SLB and TBLC, sampling errors might occur if the biopsy does not cover an affected area in cases of patchy impairment by a DLD.

On the other hand, while biopsies are usually taken at multiple sites in SLB, with CT-guided transthoracic lung biopsy, the biopsy is usually performed only at one site. This can be considered another limitation of the study. In fact, as a minimally invasive technique, CT-guided transthoracic lung biopsy is usually performed at a single site in order to minimize the risk of complications. However, all the cases included in the present study were discussed at the DLD multidisciplinary meeting prior to the procedure, and the biopsy site was chosen according to the presumptive higher diagnostic yield and taking into account the distribution of the radiologic abnormalities. After performing the biopsy, the interventional radiologist 
evaluated the specimen obtained macroscopically, and, if this was considered unsuitable, a second biopsy was performed near the area. Nevertheless, we recognize the relevance of obtaining biopsies from multiple sites, especially when UIP or NSIP is suspected, since both these patterns can coexist in the same patient and may also be associated with other entities, such as HP. However, the cases with UIP or NSIP in our series corresponded to patients who presented no conditions for further invasive procedures.

Diagnostic decisions with respect to patients with DLD must be taken on an individual basis. In specific patients, lung biopsy might provide valuable diagnostic information and could therefore confirm diagnosis of a specific DLD. The decision as to which histological sampling procedure is the most appropriate depends on the availability of the different methods in the various centers, the experience of health care professionals, the diagnostic yield of the technique in the specific context, the general status of the patient, and the patient's preferences.

In conclusion, this study describes our experience and provides important insights into the role of CT-guided transthoracic lung biopsy in the diagnosis of DLD, specifically, in radiologic patterns in which the diagnostic yield was higher, such as consolidation and nodular pattern. Given the low complication rates, CT-guided transthoracic lung biopsy can be considered an alternative in patients whose respiratory function is seriously impaired and in those with substantial comorbidities, where more invasive procedures cannot be performed for reasons of safety.

\section{Disclosure Statement}

The authors declare that no funding was received for this paper. The authors have no conflicts of interest to declare.

\section{References}

1 Behr J: Approach to the diagnosis of interstitial lung disease. Clin Chest Med 2012;33:110.

2 Ryu JH, Daniels CE, Hartman TE, Yi ES: Diagnosis of interstitial lung diseases. Mayo Clin Proc 2007;82:976-986.

3 Meyer KC: Diagnosis and management of interstitial lung disease. Transl Respir Med 2014;2:4.

4 Travis WD, Costabel U, Hansell DM, King TE Jr, Lynch DA, Nicholson AG, Ryerson CJ, Ryu JH, Selman M, Wells AU, Behr J, Bouros D, Brown KK, Colby TV, Collard HR, Cordeiro CR, Cottin V, Crestani B, Drent M, Dudden RF, Egan J, Flaherty K, Hogaboam C, Inoue $\mathrm{Y}$, Johkoh T, Kim DS, Kitaichi M, Loyd J, Martinez FJ, Myers J, Protzko S, Raghu G, Richeldi L, Sverzellati N, Swigris J, Valeyre D; ATS/ERS Committee on Idiopathic Interstitial Pneumonias: An official American Thoracic Society/European Respiratory Society statement: update of the international multidisciplinary classification of the idiopathic interstitial pneumonias. Am J Respir Crit Care Med 2013;188:733748.

5 Raghu G, Collard HR, Egan JJ, Martinez FJ, Behr J, Brown KK, Colby TV, Cordier JF, Flaherty KR, Lasky JA, Lynch DA, Ryu JH, Swigris JJ, Wells AU, Ancochea J, Bouros D, Carvalho C, Costabel U, Ebina M, Hansell DM, Johkoh T, Kim DS, King TE Jr, Kondoh Y, Myers J, Müller NL, Nicholson AG, Richeldi L, Selman M, Dudden RF, Griss BS, Protzko SL. Schünemann HJ; ATS/ERS/JRS/ALAT Committee on Idiopathic Pulmonary Fibro- sis: An official ATS/ERS/JRS/ALAT statement: idiopathic pulmonary fibrosis: evidence-based guidelines for diagnosis and management. Am J Respir Crit Care Med 2011;183:788-824.

6 Walsh SL, Wells AU, Desai SR, Poletti V, Piciucchi S, Dubini A, Nunes H, Valeyre D, Brillet PY, Kambouchner M, Morais A, Pereira JM, Moura CS, Grutters JC, van den Heuvel DA, van Es HW, van Oosterhout MF, Seldenrijk CA, Bendstrup E, Rasmussen F, Madsen LB, Gooptu B, Pomplun S, Taniguchi H, Fukuoka J, Johkoh T, Nicholson AG, Sayer C, Edmunds L, Jacob J, Kokosi MA, Myers JL, Flaherty KR, Hansell DM: Multicentre evaluation of multidisciplinary team meeting agreement on diagnosis in diffuse parenchymal lung disease: a case-cohort study. Lancet Respir Med 2016; 4:557-565.

7 Bradley B, Branley HM, Egan JJ, Greaves MS, Hansell DM, Harrison NK, Hirani N, Hubbard R, Lake F, Millar AB, Wallace WA, Wells AU, Whyte MK, Wilsher ML; British Thoracic Society Interstitial Lung Disease Guideline Group, British Thoracic Society Standards of Care Committee; Thoracic Society of Australia; New Zealand Thoracic Society; Irish Thoracic Society: Interstitial lung disease guideline: the British Thoracic Society in collaboration with the Thoracic Society of Australia and New Zealand and the Irish Thoracic Society. Thorax 2008;63(suppl 5):v1-v58.

8 Descombes E, Gardiol D, Leuenberger P: Transbronchial lung biopsy: an analysis of
530 cases with reference to the number of samples. Monaldi Arch Chest Dis 1997;52: 324-329.

9 Casoni GL, Cordeiro CR Jr, Tomassetti S, Romagnoli $M$, Chilosi $M$, Cancellieri A, et al: The role of transbronchial biopsy in the diagnosis of diffuse parenchymal lung diseases: pro. Rev Port Pneumol 2012;18:57-60.

10 Babiak A, Hetzel J, Krishna G, Fritz P, Moeller P, Balli T, Hetzel M: Transbronchial cryobiopsy: a new tool for lung biopsies. Respiration 2009;78:203-208.

11 Pajares V, Puzo C, Castillo D, Lerma E, Montero MA, Ramos-Barbón D, Amor-Carro O, Gil de Bernabé A, Franquet T, Plaza V, Hetzel J, Sanchis J, Torrego A: Diagnostic yield of transbronchial cryobiopsy in interstitial lung disease: a randomized trial. Respirology 2014 19:900-906.

12 Casoni GL, Tomassetti S, Cavazza A, Colby TV, Dubini A, Ryu JH, Carretta E, Tantalocco P, Piciucchi S, Ravaglia C, Gurioli C, Romagnoli M, Gurioli C, Chilosi M, Poletti V: Transbronchial lung cryobiopsy in the diagnosis of fibrotic interstitial lung diseases. PLoS One 2014;9:e86716.

13 Nguyen W, Meyer KC: Surgical lung biopsy for the diagnosis of interstitial lung disease: a review of the literature and recommendations for optimizing safety and efficacy. Sarcoidosis Vasc Diffuse Lung Dis 2013;30:3-16.

14 Park JH, Kim DK, Kim DS, Koh Y, Lee SD, Kim WS, Kim WD, Park SI: Mortality and risk factors for surgical lung biopsy in patients with idiopathic interstitial pneumonia. Eur J Cardiothorac Surg 2007;31:1115-1119. 
15 Fibla JJ, Molins L, Blanco A, Royo I, Martínez Vallina P, Martínez N, García Barajas S, Gomez A, Estors M, Moldes M, Fernández E, Xaubet A: Video-assisted thoracoscopic lung biopsy in the diagnosis of interstitial lung disease: a prospective, multi-center study in 224 patients. Arch Bronconeumol 2012;48:81-85.

16 Blanco M, Obeso GA, Durán JC, Rivo JE, García-Fontán E, Peña E, Rodríguez M, Albort J, Cañizares MA: Surgical lung biopsy for diffuse lung disease. Our experience in the last 15 years. Rev Port Pneumol 2013;19:59-64.

17 Hansell DM, Bankier AA, MacMahon H, McLoud TC, Müller NL, Remy J: Fleischner Society: glossary of terms for thoracic imaging. Radiology 2008;246:697-722.

18 Pellegrino R, Viegi G, Brusasco V, Crapo RO, Burgos F, Casaburi R, Coates A, van der Grinten CP, Gustafsson P, Hankinson J, Jensen R, Johnson DC, MacIntyre N, McKay R, Miller MR, Navajas D, Pedersen OF, Wanger $\mathrm{J}$ : Interpretative strategies for lung function tests. Eur Respir J 2005;26:948-968.

19 Klech H, Pohl W: Technical recommendations and guidelines for bronchoalveolar lavage (BAL). Report of the European Society of Pneumology Task Group. Eur Respir J 1989; 2:561-585.

20 Zhang HF, Zeng XT, Xing F, Fan N, Liao MY: The diagnostic accuracy of CT-guided percutaneous core needle biopsy and fine needle aspiration in pulmonary lesions: a meta-analysis. Clin Radiol 2016;71:e1-e10.

21 Aktaş AR, Gözlek E, Yılmaz Ö, Kayan M, Ünlü N, Demirtaş H, Değirmenci B, Kara M: CT-guided transthoracic biopsy: histopathologic results and complication rates. Diagn Interv Radiol 2015;21:67-70.

22 Wu CC, Maher MM, Shepard JA: CT-guided percutaneous needle biopsy of the chest: preprocedural evaluation and technique. AJR Am J Roentgenol 2011;196:W511-W514.

23 Laspas F, Roussakis A, Efthimiadou R, Papaioannou D, Papadopoulos S, Andreou J: Percutaneous CT-guided fine-needle aspiration of pulmonary lesions: results and complications in 409 patients. J Med Imaging Rad Oncol 2008;52:458-462.

24 Jae LI, June IH, Miyeon Y, Kwanseop L, Yul L, Hoon BS: Percutaneous core needle biopsy for small ( $\leq 10 \mathrm{~mm}$ ) lung nodules: accurate diagnosis and complication rates. Diagn Interv Radiol 2012;18:527-530.

25 Tian P, Wang Y, Li L, Zhou Y, Luo W, Li W: CT-guided transthoracic core needle biopsy for small pulmonary lesions: diagnostic performance and adequacy for molecular testing. J Thorac Dis 2017;9:333-343.

26 Charig MJ, Phillips AJ: CT-guided cutting needle biopsy of lung lesions - safety and ef- ficacy of an out-patient service. Clin Radiol 2000;55:964-969.

27 Walsh SLF: Multidisciplinary evaluation of interstitial lung diseases: current insights: Number 1 in the Series "Radiology" Edited by Nicola Sverzellati and Sujal Desai. Eur Respir Rev 2017;26:170002.

28 Flaherty KR, King TE Jr, Raghu G, Lynch JP 3rd, Colby TV, Travis WD, Gross BH, Kazerooni EA, Toews GB, Long Q, Murray S, Lama VN, Gay SE, Martinez FJ: Idiopathic interstitial pneumonia: what is the effect of a multidisciplinary approach to diagnosis? Am J Respir Crit Care Med 2004;170:904-910.

29 Shah SS, Tsang V, Goldstraw P: Open lung biopsy: a safe, reliable and accurate method for diagnosis in diffuse lung disease. Respiration 1992;59:243-246.

30 Morell F, Reyes L, Doménech G, Gracia J, Majó J, Ferrer J: Diagnoses and diagnostic procedures in 500 consecutive patients with clinical suspicion of interstitial lung disease. Arch Bronconeumol 2008;44:185-191.

31 Rotolo N, Imperatori A, Dominioni L, Facchini A, Conti V, Castiglioni M, Spanevello A: Efficacy and safety of surgical lung biopsy for interstitial disease. Experience of 161 consecutive patients from a single institution in Italy. Sarcoidosis Vasc Diffuse Lung Dis 2015;32: 251-258.

32 Hutchinson JP, Fogarty AW, McKeever TM, Hubbard RB: In-Hospital Mortality after surgical lung biopsy for interstitial lung disease in the United States. 2000 to 2011. Am J Respir Crit Care Med 2016;193:1161-1167.

33 Raj R, Raparia K, Lynch DA, Brown KK: Surgical lung biopsy for interstitial lung diseases. chest 2017;151:1131-1140.

34 Blackhall V, Asif M, Renieri A, Civitelli S, Kirk A, Jilaihawi A, Granato F: The role of surgical lung biopsy in the management of interstitial lung disease: experience from a single institution in the UK. Interact Cardiovasc Thorac Surg 2013;17:253-257.

35 Durheim MT, Kim S, Gulack BC, Burfeind WR, Gaissert HA, Kosinski AS, Hartwig MG: Mortality and respiratory failure after thoracoscopic lung biopsy for interstitial lung disease. Ann Thorac Surg 2017;104:465-470.

36 Kaarteenaho R: The current position of surgical lung biopsy in the diagnosis of idiopathic pulmonary fibrosis. Respir Res 2013;14:43.

37 Kropski JA, Pritchett JM, Mason WR, Sivarajan L, Gleaves LA, Johnson JE, Lancaster LH, Lawson WE, Blackwell TS, Steele MP, Loyd JE, Rickman OB: Bronchoscopic cryobiopsy for the diagnosis of diffuse parenchymal lung disease. PLoS One 2013;8:e78674.

38 Dhooria S, Sehgal IS, Aggarwal AN, Behera D, Agarwal R: Diagnostic yield and safety of cryoprobe transbronchial lung biopsy in diffuse parenchymal lung diseases: systematic review and meta-analysis. Respir Care 2016; 61:700-712.

39 Marçôa R, Linhas R, Apolinário D, Campainha S, Oliveira A, Nogueira C, Loureiro A, Almeida J, Costa F, Wen X, Neves S: Diagnostic yield of transbronchial lung cryobiopsy in interstitial lung diseases. Rev Port Pneumol 2017;23:296-298.

40 Miao L, Wang Y, Li Y, Ding J, Chen L, Dai J, Cai H, Xiao Y, Cao M, Huang M, Qiu Y, Meng F, Fan X, Zhang D, Song Y: Lesion with morphologic feature of organizing pneumonia (OP) in CT-guided lung biopsy samples for diagnosis of bronchiolitis obliterans organizing pneumonia (BOOP): a retrospective study of 134 cases in a single center. J Thorac Dis 2014;6:1251-1260.

41 Metzger F, Pernet D, Manzoni P, Ranfaing E, Dalphin J-C: The contribution of CT-guided transthoracic lung biopsy to the diagnosis of organising pneumonia. Revue Maladies Respirat 2010;27:e6-e16.

42 Poulou LS, Tsangaridou I, Filippoussis P, Sidiropoulou N, Apostolopoulou S, Thanos L: Feasibility of CT-guided percutaneous needle biopsy in early diagnosis of BOOP. Cardiovasc Intervent Radiol 2008;31:1003-1007.

43 Esteves C, Costa FR, Redondo MT, Moura CS, Guimarães S, Morais A, Pereira JM: Pleuroparenchymal fibroelastosis: role of high-resolution computed tomography (HRCT) and CTguided transthoracic core lung biopsy. Insights Imaging 2016;7:155-162.

44 Lohela P, Tikkakoski T, Ammala K, Strengell L, Suramo I, Repo UK: Diagnosis of diffuse lung disease by cutting needle biopsy. Acta Radiol 1994;35:251-254.

45 Oliveira M, Pereira T, Dias M, Sanches A, Campainha S, Neves S: Study of CT-guided core needle biopsy in patients with interstitial lung diseases: diagnostic yield and complications. Rev Port Pneumol 2016;22:353354

46 Schulze R, Seebacher G, EnderesB, Kugler G Fischer JR, Graeter TP: Complications in CTguided, semi-automatic coaxial core biopsy of potentially malignant pulmonary lesions. Fortschr Röntgenstr 2015;187:697-702.

47 Sigurdsson MI, Isaksson HJ, Gudmundsson G, Gudbjartsson T: Diagnostic surgical lung biopsies for suspected interstitial lung diseases: a retrospective study. Ann Thorac Surg 2009;88:227-232.

48 Kondoh Y, Taniguchi H, Kitaichi M, Yokoi T, Johkoh T, Oishi T, Kimura T, Nishiyama O, Kato K, du Bois RM: Acute exacerbation of interstitial pneumonia following surgical lung biopsy. Respir Med 2006;100:1753-1759.
Diagnostic Yield of CT-Guided

Transthoracic Lung Biopsy in DLD
Respiration 2018;96:455-463

DOI: $10.1159 / 000489934$ 